\title{
O forno solar como ponte entre a física e o conforto das edificações ${ }^{+*}$
}

Jonas Cegelka da Silva ${ }^{1}$

Instituto Federal de Educação, Ciência e Tecnologia Farroupilha

Campus Santa Rosa - RS

Doutorando no Programa de Pós-Graduação em Educação em Ciências:

Química da Vida e Saúde da Universidade Federal de Santa Maria

Renata Rotta ${ }^{1}$

Instituto Federal de Educação, Ciência e Tecnologia Farroupilha

Campus Santa Rosa - RS

Isabel Krey Garcia ${ }^{l}$

Universidade Federal de Santa Maria

Santa Maria - RS

\section{Resumo}

$O$ referido trabalho é fruto de uma prática interdisciplinar entre a física e o conforto das edificações para alunos do segundo ano do ensino médio do curso técnico integrado de edificações. Tendo como suporte teórico as teorias da aprendizagem significativa, da aprendizagem significativa crítica, dos campos conceituais e da interdisciplinaridade, foi proposto aos alunos que construíssem um forno solar com materiais de baixo custo. Para isso, os mesmos receberam oito situações que norteavam suas buscas pelos melhores materiais a serem utilizados. Essas situações foram respondidas, inicialmente pelos alunos, a partir de pesquisa realizada e após, sistematizadas na turma. Como resultado, foi possível obter indícios de aprendizagem significativa elou significativa crítica dos conceitos abordados, tais como propagação do calor e fechamentos (opacos e transparentes). Durante a explanação sobre a construção do forno, os alunos externalizaram os conhecimentos aprendidos de forma mais ampla, fazendo contrapontos com o conforto térmico em uma edificação.

\footnotetext{
${ }^{+}$The solar oven as a bridge between physics and comfort in building

* Recebido: junho de 2017. Aceito: julho de 2018.

${ }^{1}$ E-mails: jonas.silva@iffarroupilha.edu.br; renata.rotta@iffarroupilha.edu.br; ikrey69@gmail.com
} 
Palavras-chave: Interdisciplinaridade; Física Térmica; Aprendizagem Significativa; Campos Conceituais; Forno Solar.

\begin{abstract}
The present work is a result of an interdisciplinary practice between physics and comfort in buildings for second grade students of Highschool-integrated to Vocational Training in Building Construction. With the theoretical background of meaningful learning, critical meaningful learning, conceptual fields and interdisciplinarity, the task of building a low cost material solar oven was assigned to the students. Hence, eight situations were given to students in order to guide them to select the best materials. These situations were answered, first by the students, from previous research and then, sistematized in class. As a result, indications of meaningful learning and/or critical meaningful learning of the concepts covered such as heat propagation and closures (opaque and transparent) were obtained. During the explanation about oven construction, the students expressed the learned knowledge in a broad way, pointing out the interrelations with thermal comfort in buildings.
\end{abstract}

Keywords: Interdisciplinarity; Thermal Physics; Meaningful Learning; Conceptual Fields; Solar Oven.

\title{
I. Introdução
}

Pensar uma prática interdisciplinar dentro de um Instituto Federal requer, antes de tudo, conhecer o que os documentos legais dessas instituições apresentam quanto às propostas e políticas pedagógicas. Fomentando um caráter de integração dos saberes, uma das suas finalidades é promover a integração e a verticalização da educação básica à educação profissional e educação superior (BRASIL, 2008). Nesse aspecto, prima-se por uma educação que possibilite ao sujeito o desenvolvimento de sua capacidade de gerar conhecimentos a partir de uma prática interativa com a realidade, buscando romper com a fragmentação do saber (PACHECO, 2011).

No Curso Técnico em Edificações Integrado ao Ensino Médio do Instituto Federal de Educação, Ciência e Tecnologia Farroupilha (IFFAR), Campus Santa Rosa, espaço no qual a investigação foi realizada, são contemplados os conteúdos de formação técnica e os de formação geral, de maneira contextualizada, procurando desenvolver metodologias e práticas educativas integradoras do teórico-prático e complementadoras do saber-fazer (BRASIL, 2014). Algumas práticas interdisciplinares ocorrem durante a realização das Práticas Profissionais 
Integradas (PPI), as quais estimulam a pesquisa como princípio educativo, promovendo a interdisciplinaridade e a indissociabilidade entre ensino, pesquisa e extensão. A PPI deve articular os conhecimentos trabalhados em no mínimo, quatro disciplinas contemplando necessariamente disciplinas da área básica e da área técnica (ibid., 2014).

Objetivando promover uma prática interdisciplinar no desenvolvimento regular das aulas de física e conforto das edificações do segundo ano do referido curso, proporcionando aos alunos a construção global do conhecimento e a possibilidade de uma aprendizagem significativa e/ou significativa crítica, foi elaborado um projeto de pesquisa, abrangendo os conceitos da calorimetria e suas relações às propriedades térmicas dos materiais utilizados nas edificações. A aplicação da pesquisa se deu no primeiro semestre de 2016 e culminou com a construção de fornos solares com materiais de baixo custo a partir do emprego dos conceitos abordados nas disciplinas.

Como forma de transcender a multidisciplinaridade, Japiassu (1976) argumenta que o papel específico da atividade interdisciplinar consiste, primordialmente, em lançar uma ponte para religar as fronteiras que haviam sido estabelecidas anteriormente entre as disciplinas. Nessa perspectiva é que propomos a construção do forno solar, cujo princípio de funcionamento está diretamente relacionado à elevação da temperatura em seu interior, e que necessita do entendimento de conceitos de ambas as disciplinas para ser entendido.

As aulas foram desenvolvidas a partir daquilo que os alunos traziam de bagagem conceitual, favorecendo que a aprendizagem ocorresse de forma significativa e/ou significativa crítica, por meio da motivação para que relacionassem o novo conhecimento àquele já existente em suas estruturas cognitivas. Nesse trabalho, como já descrito, por meio de uma prática interdisciplinar entre física e conforto das edificações, procuramos indícios de aprendizagem significativa e/ou significativa crítica dos conceitos da calorimetria, a partir da construção de um forno solar, o qual foi idealizado a partir da apresentação de diversas situações, à luz da teoria de Vergnaud $(1986,1998,2007)$ que embasaram a busca pela escolha dos materiais e das técnicas a serem utilizadas.

\section{Referencial teórico}

Pensar um ensino que possibilite ao aluno a construção de um conhecimento global, onde as partes se encaixam para explicar os fenômenos, requer que as disciplinas transponham o isolamento que comumente acontece nas salas de aula, o que significa que se pode dizer que se está no terreno da interdisciplinaridade quando

um objeto é estudado em diferentes disciplinas (...) sob diferentes perspectivas, sendo as práticas dos referidos professores alteradas de modo a fomentarem o estabelecimento de ligações de complementaridade entre essas disciplinas e a favorecer a integração das aprendizagens dos alunos (COSTA, 2012, p. 104). 
Porém, nem sempre é fácil desenvolver um trabalho interdisciplinar, haja vista que, "cada disciplina pretende primeiro fazer reconhecer sua soberania territorial, e, à custa de algumas magras trocas, as fronteiras confirmam-se em vez de se desmoronar" (MORIN, 2005, p. 135). Para Costa (2012), algumas das dificuldades encontradas correspondem à falta de diálogo entre os professores, necessidade de cumprimento do programa de estudo, falta de formação específica e falta de receptividade, por parte dos colegas, para o desenvolvimento desse tipo de prática.

Contudo, muitas vezes a não aceitação por este tipo de prática é levada a cabo acreditando-se que na interdisciplinaridade o ensino dos saberes próprios de cada disciplina é deixado de lado, mas isto não é, de fato, a condição para um ensino interdisciplinar. Ao contrário, "o professor interdisciplinar percorre as regiões fronteiriças flexíveis onde o "eu" convive com o "outro" sem abrir mão de suas características, possibilitando a interdependência, o compartilhamento, o encontro, o diálogo e as transformações" (TRINDADE, 2008, p. 82).

O trabalho multidisciplinar, em muitos casos, é confundido com o interdisciplinar, mas na verdade não tem muitas semelhanças. Na multidisciplinaridade, de acordo com Santomé (1998), não existe a explicitação clara das possíveis relações entre as disciplinas e os alunos não conseguem transferir espontaneamente os conhecimentos de uma disciplina para outra, o que favorece que esses conhecimentos permaneçam engavetados em compartimentos isolados. E é essa perspectiva que deve ser transposta, para chegar-se no terreno do fazer interdisciplinar, facilitando que a aprendizagem ocorra de forma significativa e/ou significativa crítica.

As aulas pautadas apenas na exposição de conteúdo de forma estanque e compartimentalizada, de modo a requerer do aluno exclusivamente a reprodução daquilo que conseguiu memorizar, sem margens para o debate e para questionamentos, implica o estabelecimento apenas de uma aprendizagem mecânica, sem significado para o aluno. Indo além dessa visão, "pensar pedagogicamente os saberes escolares, em uma perspectiva metodológica e significativa para os alunos, implica desenvolver ações que tirem os alunos da inércia, desencadeando reações mais positivas e propositivas em relação à construção do conhecimento escolar" (CASTELLAR; MORAES, 2012, p. 131).

Nesse sentido, a aprendizagem significativa de Ausubel se refere a "um processo por meio do qual uma nova informação relaciona-se com um aspecto especificamente relevante da estrutura de conhecimento do indivíduo" (MOREIRA, 1999, p. 153). O resultado da interação que ocorre entre a nova informação a ser aprendida e a estrutura cognitiva existente é uma assimilação de antigos e novos significados que contribui para a diferenciação e enriquecimento dessa estrutura.

Ausubel defende que para ocorrer aprendizagem significativa, duas condições devem ser satisfeitas: $(i)$ o material a ser ensinado deve ser potencialmente significativo e; (ii) o aluno deve estar predisposto a aprender. Para o material ser potencialmente significativo, "deve estar relacionado de forma não arbitrária (plausível, sensível e não aleatória) e não literal com 
qualquer estrutura cognitiva apropriada e relevante" (AUSUBEL, 2003, p.1). Como é uma teoria de vertente construtivista (MOREIRA, 1999), que busca entender como ocorre a compreensão, o armazenamento dos significados e o uso das informações na mente do aluno, a variável isolada mais importante para a aprendizagem significativa de novos conhecimentos é aquilo que o aluno já sabe - os subsunçores existentes na sua estrutura cognitiva (AUSUBEL, 2003).

A investigação dos conhecimentos prévios dos alunos "leva o professor a ter como referência e introduzir ao estudo as informações trazidas por seus alunos, fazendo com que o conteúdo seja desafiador" (CASTELLAR; MORAES, 2012, p. 124). Nosso trabalho esteve sempre imbricado nessa concepção, de modo que buscávamos promover uma evolução no campo conceitual da calorimetria, a partir daquilo que os alunos traziam de bagagem.

Para além das ideias de Ausubel, é necessário que a aprendizagem significativa ocorra de forma crítica, uma vez que, em uma sociedade contemporânea, "ao mesmo tempo que é preciso viver nessa sociedade, integrar-se a ela, é necessário também ser crítico dela, distanciar-se dela e de seus conhecimentos quando ela está perdendo rumo" (MOREIRA, 2009, p. 42). Assumindo os mesmos pressupostos defendidos por Ausubel, Moreira lança mão de uma série de princípios para que se promova uma aprendizagem significativa crítica. Alguns desses princípios incluem, de acordo com Moreira (2006, 2009 e 2010):

1. Princípio da interação social e do questionamento: por meio da interação é que aluno e professor passam a compartilhar significados para os conceitos. As perguntas dos alunos podem evidenciar a aprendizagem significativa crítica ao serem elaboradas de maneira não arbitrária e não literal a partir dos seus conhecimentos prévios. Por isso promovemos o debate durante as aulas, de modo que os alunos traziam suas considerações e/ou dúvidas, externalizando suas ideias a partir de suas experiências.

2. Princípio da consciência semântica: o significado está nas pessoas e não nas palavras, uma vez que as pessoas atribuem significado às palavras, sempre a partir de sua experiência. Nos episódios de ensino-aprendizagem, além de professor e aluno compartilharem significados, deve-se ter clareza de que esses significados são pessoais, construídos a partir daquilo que o aluno já sabe.

3. Princípio da desaprendizagem: algumas vezes o aluno deve desaprender (não usar) determinado subsunçor que possa estar servindo de obstáculo cognitivo para, aí sim, aprender de forma significativa o novo conhecimento. Porém, sabemos que esse processo não é simples, uma vez que o aluno nem sempre abandona seu saber anterior.

4. Princípio da diversidade de estratégias: para que a aprendizagem significativa seja crítica, o professor deve abandonar o uso exclusivo do quadro negro como forma atribuída ao comportamentalismo - o professor escreve, o aluno copia, decora e reproduz. Deve sim utilizar diferentes estratégias de ensino que promovam a participação crítica e responsável dos alunos. Desse princípio decorre o ensino pela pesquisa, que propusemos neste trabalho. 
Esses princípios também devem possibilitar o fim da narrativa enquanto estratégia de ensino. Para que os alunos sejam promotores de sua aprendizagem, o professor deve permitir que trabalhem em grupo, discutam os conceitos, questionem e façam contrapontos. As situações, à luz da teoria de Vergnaud, tal como estruturadas, almejam motivar os alunos ao diálogo em grupo e à formulação de questionamentos, a partir de sua bagagem conceitual e experiencial.

Um campo conceitual, como definido por Vergnaud (1986), corresponde a um conjunto de situações cujo domínio requer uma variedade de conceitos, de procedimentos e de representações simbólicas em estreita conexão, tendo como premissas que um conceito não se forma com um só tipo de situação; que a análise de uma situação requer a utilização de vários conceitos e; que a formação de um conceito demora um período de tempo longo, com avanços e retrocessos, interações e desníveis. Em um campo conceitual, as situações são quem dão sentido ao conceito; os invariantes operatórios constituem as diferentes propriedades do conceito; e as representações simbólicas são usadas para indicar os invariantes operatórios.

Se os conceitos tornam-se significativos por meio de diversas situações, estas são a principal entrada de um campo conceitual. As situações a que Vergnaud se refere são entendidas no sentido de tarefa e/ou problema, e não no sentido de situação didática. No entanto, de acordo com Vergnaud (2007), não se pode apresentar sempre o mesmo tipo de situações, mas também não se deve oferecer situações muito complexas, uma vez que o conhecimento evolui na medida em que novas situações fazem com que os sujeitos se vejam desprovidos de indicativos de solução.

No processo de ensino-aprendizagem, Vergnaud (1998) argumenta que professores são mediadores e seu papel consiste essencialmente em ajudar os alunos a desenvolverem seus repertórios de esquemas e representações. E a primeira ação de mediação é, de fato, a seleção das situações que serão propostas. Nesse sentido, o professor deve prover diferentes tipos de situações para possibilitar que os alunos aperfeiçoem seus esquemas. Para que isso aconteça, os alunos devem ser desestabilizados cognitivamente, tomando consciência de que seus esquemas não dão conta de responder por completo a nova situação apresentada.

Sendo a teoria dos campos conceituais relativa sobre a organização e relação de conceitos a partir de diferentes classes de situações e da relação dos sujeitos para com estas, o papel do professor é prover situações frutíferas para que o aluno domine progressivamente certo campo conceitual. E é com esse intuito que apresentamos aos alunos o conjunto de situações norteadoras, descritas a seguir, para ajudá-los na solução do problema de construção do forno solar. 


\section{Materiais e métodos}

O trabalho foi desenvolvido em uma turma do segundo ano do ensino médio, composta por 26 alunos, do curso técnico integrado em edificações, do IFFAR, Campus Santa Rosa, no primeiro semestre do ano de 2016. As disciplinas envolvidas foram a física e o conforto das edificações e os conceitos abordados foram referentes à calorimetria e suas relações para com as propriedades térmicas dos materiais. Dentre esses conceitos, se podem citar energia cinética, energia interna, temperatura, equilíbrio térmico, calor (sensível e latente), processos de transferência de calor, mecanismos termorreguladores e fechamentos opacos e transparentes.

Não necessariamente o estudo desses conceitos aconteceu na sequência apresentada, o que indica um caminho para acabar com a linearidade dos conteúdos muito frequente nas escolas e que favorece a interdisciplinaridade. Também, alguns deles não foram trabalhados com detalhes por uma disciplina, uma vez que a outra estava abordando-os com mais ênfase. Exemplo disso são os processos de propagação do calor que foram mais aprofundados por conforto das edificações, enquanto o estudo das trocas de calor sensível e latente foi intensificado nas aulas de física.

Como propusemos um caráter interdisciplinar para a investigação, a primeira etapa consistiu em um diálogo entre os professores das duas disciplinas, objetivando o estabelecimento de conexões dos conceitos a serem abordados, a forma de conduzir as aulas, como avaliar os alunos e definir o plano de execução das atividades. Esses diálogos sucederam-se ao longo do semestre letivo, sempre que percebíamos necessidade de trocas conceituais, metodológicas e de reflexão sobre o trabalho.

Nossa motivação para o fazer interdisciplinar foi o forno solar, dispositivo que funciona como uma estufa, mantendo seu interior aquecido. Os alunos dividiram-se em seis grupos e precisaram resolver o seguinte problema: (a) elaborar um roteiro de construção de um forno solar com materiais de baixo custo, descrevendo os materiais utilizados e o motivo da escolha desses; (b) a partir do roteiro, construir o forno e fazer registros de todas as etapas e; (c) criar estratégias, fazer testes e registros para que o forno tenha a melhor eficiência possível.

Para ajudá-los na resolução do problema, foi elaborado pelos professores das duas disciplinas, um conjunto de oito situações norteadoras, descritas a seguir, relativas a conceitos importantes de serem observados na construção do forno e que, depois de pesquisadas pelos grupos de alunos, eram debatidas na turma, como forma de sistematização dos conceitos. Cabe salientar que essa sistematização ocorria nas aulas das duas disciplinas, de forma que os professores faziam os conceitos convergirem, possibilitando que os alunos também percebessem a conexão entre eles.

A etapa final do trabalho consistiu de uma apresentação dos resultados alcançados, sendo que, nesse momento, os dois professores (física e conforto das edificações) puderam fazer questionamentos e apontamentos. Desde a proposição do problema até a apresentação 
do trabalho, os alunos tiveram dois meses para dar conta das etapas. Destacamos que propusemos um problema amplo, deixando os alunos pensarem estratégias de resolução, corroborando com Borges (2002) que defende que as aulas experimentais podem proporcionar oportunidades para que os mesmos criem e testem suas hipóteses, planejem e executem ações metodológicas, buscando produzir resultados confiáveis.

Quanto aos níveis de investigação no laboratório didático, Tamir (1991, apud BORGES, 2002), propõe diversos níveis (Quadro 1), que vão desde os problemas, os procedimentos e as conclusões fornecidos pelo professor, até o caso em que todas as etapas são abertas, de proposição dos alunos.

Quadro 1 - Níveis de investigação no laboratório didático.

\begin{tabular}{|c|c|c|c|}
\hline Nível de investigação & Problemas & Procedimentos & Conclusões \\
\hline Nível 0 & Dados & Dados & Dados \\
\hline Nível 1 & Dados & Dados & Em aberto \\
\hline Nível 2 & Dados & Em aberto & Em aberto \\
\hline Nível 3 & Em aberto & Em aberto & Em aberto \\
\hline
\end{tabular}

Fonte: Tamir (1991, apud BORGES, 2002).

De acordo com a classificação acima, caracterizamos nossa atividade no nível 2 de investigação, uma vez que, dado o problema, os alunos é que deveriam decidir como e que dados coletar, fazer as medições e obter suas conclusões. Defendemos essa caracterização assumindo que as situações norteadoras não se constituíram de procedimentos metodológicos para a efetivação do trabalho, mas sim, elementos motivadores e direcionadores para a pesquisa. As situações norteadoras às quais nos referimos são:

Situação 1: Ao ir à praia, é notável a diferença entre a temperatura da água do mar e da areia. De manhã, por exemplo, a areia está bem mais quente que a água do mar; à noite, no entanto, a areia está fria e a água do mar está morna. Por que isso acontece? O que existe de diferente entre a areia e a água do mar?

Essa situação foi proposta com o objetivo de que os alunos utilizassem o conceito de calor específico para respondê-la. Como o calor específico da água é maior que o da areia, ela aquece mais lentamente, mas também demora mais tempo para resfriar. Este fato pode ser levado em consideração na projeção do forno, haja vista que os materiais que podem ser escolhidos demoram mais ou menos para aquecer e/ou resfriar, uma vez que substâncias diferentes possuem diferentes capacidades de armazenamento de energia interna (HEWITT, 2002).

Situação 2: Ao deixar duas colheres, uma de madeira e outra de metal, encostadas na borda de uma panela sobre a chama de um fogão, decorrido algum tempo é mais fácil segurar 
a colher de madeira do que a de metal. Por isso acontece? O que tem de diferente nas propriedades desses dois materiais?

Propomos essa situação para que os alunos externalizassem seus conhecimentos sobre a condução térmica, processo no qual há transferência de energia entre partículas, mas sem que estas se desloquem, e que é mais eficiente nos metais. Além disso, também podiam aparecer respostas referentes à sensação de frio que sentimos quando tocamos dois corpos feitos de diferentes materiais, mas que estão à mesma temperatura. As características dos materiais utilizados para a construção dos fornos dependem destes coeficientes para minimizar as trocas de energia na forma de calor com o meio externo e também facilitam ou dificultam a movimentação do forno de um local para outro após ter aquecido.

Situação 3: Na construção do formo solar, é importante que o interior do mesmo seja mais ou menos aquecido? Quais os materiais mais adequados na construção de um forno? É importante que haja perda de energia na forma de calor do interior para o exterior do mesmo?

Nessa situação os alunos deveriam fazer uma analogia do forno solar com um forno convencional, sendo que ambos devem manter seu interior aquecido. Para tal, os materiais que os constituem devem conduzir a menor quantidade possível de energia de seu interior para o exterior, garantindo, assim, que a temperatura interna seja mais alta. Pensando em um forno solar do tipo caixa, é interessante que sua tampa seja feita de vidro; já no interior devem-se utilizar materiais isolantes e reflexivos, aplicando os conceitos de reflexividade, absorvidade e condutibilidade, tais como são utilizados na seleção de materiais para a construção de uma edificação.

Situação 4: No verão, quando você sai para a praia ou para dar uma corrida na avenida, a sua camiseta é de cor clara, preferencialmente branca. Por que não se recomenda que a camiseta escolhida seja de cor escura ou até mesmo preta?

Essa situação foi proposta como forma de ajudar os alunos a decidirem as cores que o forno deveria ter, já que quando a radiação solar atinge determinado corpo, uma parcela é absorvida e outra é refletida. No entanto, os corpos claros refletem uma maior parcela dessa radiação; já os corpos escuros absorvem a maior parte dela. Levando essas propriedades em consideração, é possível reduzir as ilhas de calor, especialmente nos grandes centros urbanos, por exemplo, pintando os telhados com cores claras.

Situação 5: É extremamente recomendável que antes de sair de casa as pessoas passem protetor solar e, a cada duas horas de exposição ao Sol, façam a reaplicação do produto. Nesse sentido, o que existe entre o Sol e a Terra? Como “o calor” do Sol chega até nós?

Essa situação foi estruturada de modo que os alunos compreendessem o processo de transmissão de energia na forma de calor por irradiação que, diferentemente da condução e da convecção, pode se propagar no vácuo, por meio de ondas eletromagnéticas, que são refletidas por espelhos, por exemplo. Ao contrário, quando são absorvidas por um corpo, têm sua energia transferida a este. Sendo o fechamento superior do forno realizado com vidro, que é 
transparente à energia luminosa do Sol, mas opaco às ondas na faixa do infravermelho, o seu interior mantém-se aquecido.

Situação 6: Você já deve ter percebido que a fumaça que sai pelo cano de descarga dos carros ou do carvão queimando para assar um churrasco tende a subir. Como é a temperatura da fumaça em relação ao ar? Por que isto ocorre? Baseando-se neste fato, o ar condicionado nas nossas casas deve ser instalado na parte de cima ou de baixo da parede? E nos refrigeradores tradicionais, o freezer deve ser colocado na parte superior ou inferior? E no caso dos refrigeradores frostfree, isso faz diferença?

Nessa situação queríamos que os alunos externalizassem seus conhecimentos sobre a convecção térmica (efeito chaminé), a qual ocorre nos fluidos. Nesse processo, acontece transporte de energia, juntamente com o transporte de matéria. Para compreenderem esse processo de transferência de energia na forma de calor, os alunos também deveriam retomar o conceito de densidade, estudado no ano anterior.

Situação 7: Ao aquecer por bastante tempo uma panela de alumínio que não tem cabo de madeira ou de borracha, provavelmente você não será capaz de segurá-la sem a utilização de algum dispositivo de proteção. Enquanto aquece, a panela muda de estado físico? O que acontece enquanto a panela está no fogo? Se uma panela idêntica for colocada dentro do forno solar, o efeito é o mesmo? De onde vem a energia que faz a panela aquecer dentro do forno?

A proposição dessa situação buscou mostrar para os alunos que calor sensível é um processo de transferência de energia, em função da qual os corpos que realizam as trocas térmicas variam apenas sua temperatura sem, no entanto, sofrerem mudança de estado físico. Este é o fato, talvez, que a maioria das pessoas presencia no dia a dia, no qual os corpos variam sua temperatura, sendo os mecanismos termorreguladores acionados para manter a temperatura corporal estável.

Situação 8: Ao se colocar uma panela no fogo durante muito tempo, ela não muda de estado, mas o mesmo não ocorre com a água. Devido a que isso ocorre?

O processo de mudança de fase envolve trocas de calor, porém durante o processo, a temperatura permanece constante. A quantidade de energia na forma de calor necessária para a mudança de fase, por unidade de massa, é uma característica da substância e do tipo de mudança de fase, denominada calor latente. Essa questão é importante porque muitos alunos têm a noção de que a temperatura de um corpo aumenta indefinidamente - e sem pausas - enquanto o mesmo recebe energia na forma de calor.

A seguir serão apresentados os resultados do trabalho e sua análise, essencialmente descritiva, trará recortes de falas e materiais produzidos pelos sujeitos participantes, buscando "compreender o processo mediante o qual as pessoas constroem significados e descrever em que consistem estes mesmos significados" (BOGDAN; BIKLEN, 1994, p. 70). Os trechos das falas dos alunos que aparecem nas análises foram coletados nas aulas, nos momentos de as- 
sessoramentos para construção do protótipo, nos roteiros construídos pelos grupos, bem como durante as apresentações dos fornos, momento este que foi gravado com as devidas autorizações, sendo feita a transcrição a posteriori.

\section{Resultados e discussão}

A partir das discussões em aula e nos momentos de assessoramento de construção do forno, bem como dos roteiros construídos pelos alunos e da apresentação dos resultados, foi possível identificar o embasamento teórico necessário para abordar as situações norteadoras propostas. Com base nesses materiais, categorizamos os conceitos aplicados ao forno e os apresentamos nos quadros a seguir.

Se um forno solar tem seu princípio de funcionamento semelhante aos demais fornos, o seu interior deve manter uma temperatura relativamente alta em relação ao meio exterior, para efetivamente funcionar. Quando propusemos a Situação 3, os materiais que os alunos utilizariam na estrutura do forno, tais como isopor e jornal, deveriam garantir um bom isolamento térmico. O Quadro 2 mostra as escolhas dos materiais feitas pelos grupos, bem como a justificativa para essa escolha.

Quadro 2 - Isolamento térmico do forno solar.

\begin{tabular}{|c|c|}
\hline Grupo & Material/Propriedade: isolamento térmico \\
\hline G1 & $\begin{array}{l}\text { "A caixa menor foi revestida com isopor, deixando além do isopor, uma camada } \\
\text { de ar até a caixa maior. O ar e o isopor são importantes porque dificultam a troca } \\
\text { de calor entre o meio interno e externo, ou seja, são ótimos isolantes térmicos". }\end{array}$ \\
\hline G2 & $\begin{array}{l}\text { "[...] tem jornal e isopor porque jornal tem uma propriedade isolante, ele não foi } \\
\text { colocado completamente amassado então ficou um pouco de ar". }\end{array}$ \\
\hline G3 & $\begin{array}{l}\text { "Para que a caixa mantenha as temperaturas interiores altas o bastante para o } \\
\text { cozimento, as paredes e o fundo da caixa devem ter bom valor de isolamento, ou } \\
\text { seja, retenção de calor". }\end{array}$ \\
\hline G4 & $\begin{array}{l}\text { "Foi usado isopor para o isolamento térmico [...] quanto mais espesso o isopor, } \\
\text { mais eficiente o isolamento". }\end{array}$ \\
\hline G5 & $\begin{array}{l}\text { "A importância do isopor é que ele atuará como principal isolante térmico, não } \\
\text { deixando ocorrer perda de calor do forno para o meio externo [...] a gente esco- } \\
\text { lheu o isopor por conter ar dentro e o ar funciona como um bom isolante”. }\end{array}$ \\
\hline G6 & "A gente colocou isopor no fundo e na lateral [...] para isolar o calor". \\
\hline
\end{tabular}

O grupo G3 optou por não utilizar nenhum isolamento térmico, o que acarretou uma eficiência pequena do forno, conforme será visto à frente, ainda que explicite a necessidade de se ter um bom valor de isolamento. O grupo G6, embora tenha empregado isopor para fazer a vedação da caixa, não aponta qual o motivo dessa escolha, enquanto os demais grupos (G1, 
G2, G4 e G5) citam o fato de o isopor ter bastante ar em sua composição, o que o torna um bom isolante térmico.

Como o ar é um bom isolante térmico $(0.023 \mathrm{~W} / \mathrm{mK})$, o grupo $\mathbf{G 2}$ também utilizou jornal para fazer o isolamento, deixando-o um pouco amassado com o objetivo de agregar ar entre ele. O grupo G4 também destaca essa propriedade ao defender que utilizou uma chapa grossa de isopor em função de que quanto mais espesso o isopor, mais eficiente é o isolamento. Como argumentado pelos alunos, materiais de alta condutividade térmica podem ser utilizados como dissipadores térmicos, enquanto os de baixa condutividade térmica são bons isolantes (DUART et al., 2016). A Fig. 1 mostra o isolamento térmico com isopor do forno solar construído pelo grupo G1.

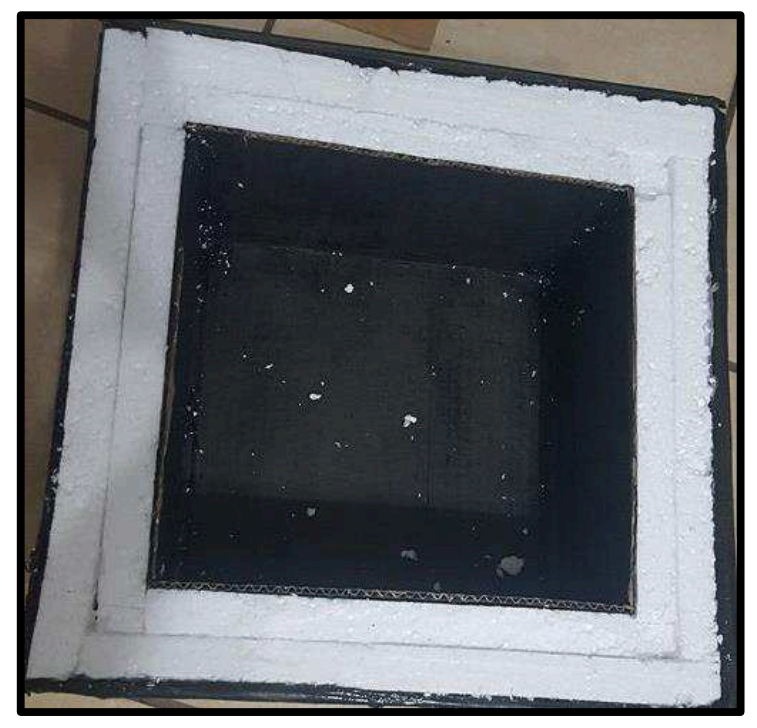

Fig. 1 - Isolamento térmico em isopor do forno solar do grupo G1. Fonte: Grupo G1.

Em se tratando da Situação 4, que envolve os conceitos de absorvidade e refletividade, a maior parte dos grupos pintou o forno solar de cor preta (Quadro 3) e utilizou papel alumínio ou espelho (Quadro 4). Uma vez que a taxa de absorvidade à radiação solar corresponde ao quociente entre a radiação solar absorvida por uma superfície e a radiação solar incidente sobre essa mesma superfície, a cor possui papel fundamental para essa propriedade. Enquanto a taxa de absorvidade da cor preta é de $97 \%$, a cor branca absorve $20 \%$ e a amarela 30\% (DUART et al., 2016).

Como os corpos escuros absorvem a maior parte da radiação incidente sobre eles, com exceção do grupo G3, que pensou em utilizar apenas o recipiente (para cozinhar algum alimento) de cor preta, os demais pintaram as faces internas e/ou externas do forno com essa cor. A Fig. 2 mostra o acabamento com tinta preta do forno solar do grupo G4. Ainda que todos os grupos tenham internalizado que, se a cor preta absorve maior quantidade de radiação, as cores claras absorvem uma parcela menor, apenas o grupo G1 externalizou essa relação. 
Quadro 3 - Justificativas para a utilização da cor preta no forno solar.

\begin{tabular}{|c|c|}
\hline Grupo & Material/Propriedade: absorvidade \\
\hline G1 & $\begin{array}{c}\text { "As caixas foram pintadas com tinta preta em todas as suas faces. A tinta preta foi } \\
\text { utilizada porque esta cor é a que mais absorve calor. Possui, portanto, o conceito de } \\
\text { absorvidade alta e o de refletividade baixa". }\end{array}$ \\
\hline G2 & $\begin{array}{l}\text { “O nosso forno solar é preto [...] porque o preto absorve mais [...] devido à alta } \\
\text { taxa de absorvidade da cor que contribuirá com a maior absorção de calor”. }\end{array}$ \\
\hline G3 & "A gente usou uma bandeja escura pra ela absorver mais". \\
\hline G4 & $\begin{array}{c}\text { "A cor preta absorve melhor a radiação solar, aquecendo mais o forno [...] a pintu- } \\
\text { ra do preto, que tem maior absorvidade". }\end{array}$ \\
\hline G5 & $\begin{array}{c}\text { "Foi feita a pintura das faces internas e externas da caixa e da tampa com tinta } \\
\text { preta, que tem a capacidade de absorver mais calor". }\end{array}$ \\
\hline G6 & $\begin{array}{c}\text { "Pintamos algumas partes das caixas de preto, inclusive o fundo, as laterais, parte } \\
\text { externa também [...] o preto absorve todas as cores do espectro". }\end{array}$ \\
\hline
\end{tabular}

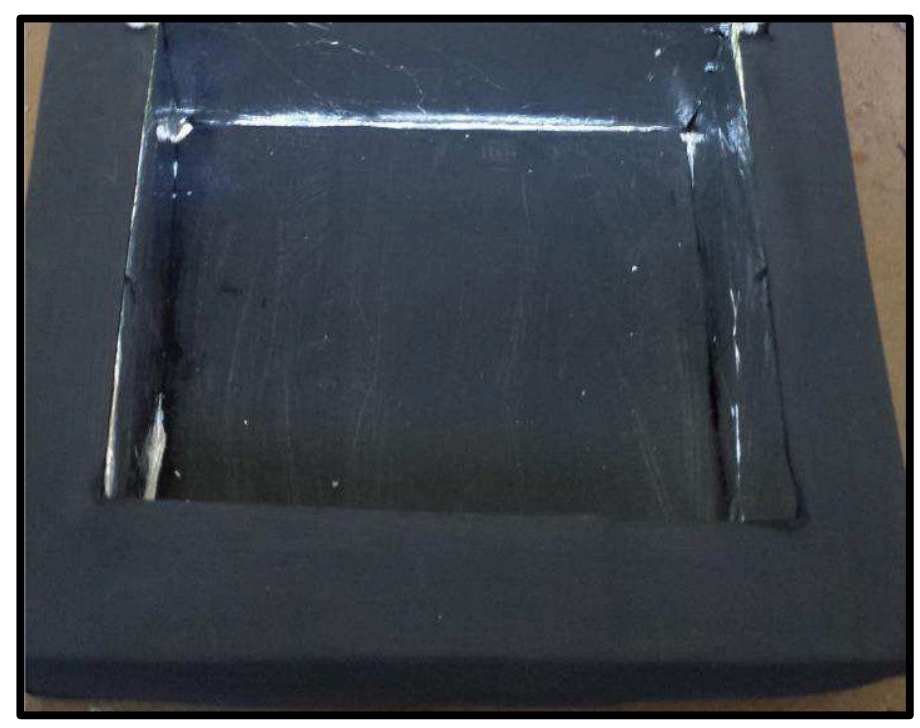

Fig. 2 - Acabamento com tinta preta do forno solar construído pelo grupo G4. Fonte: Grupo $\mathbf{G 4}$.

Objetivando concentrar a radiação no interior do forno solar, os seis grupos utilizaram papel alumínio e/ou espelhos para cumprir essa função. O motivo da escolha de um ou outro se deu, sobretudo, pelo menor custo e pela estrutura da(s) caixa(s) ser mais ou menos 
resistente. Como esses materiais diminuem a troca térmica por condução, favorecem que a radiação seja refletida no interior do forno. Relativamente à propriedade anterior, absorvidade, a refletividade tem uma relação inversamente proporcional, o que significa que corpos com baixas taxas de absorvidade têm altas taxas de refletividade. A Fig. 3 mostra o acabamento em papel alumínio para o forno solar construído pelo grupo G5.

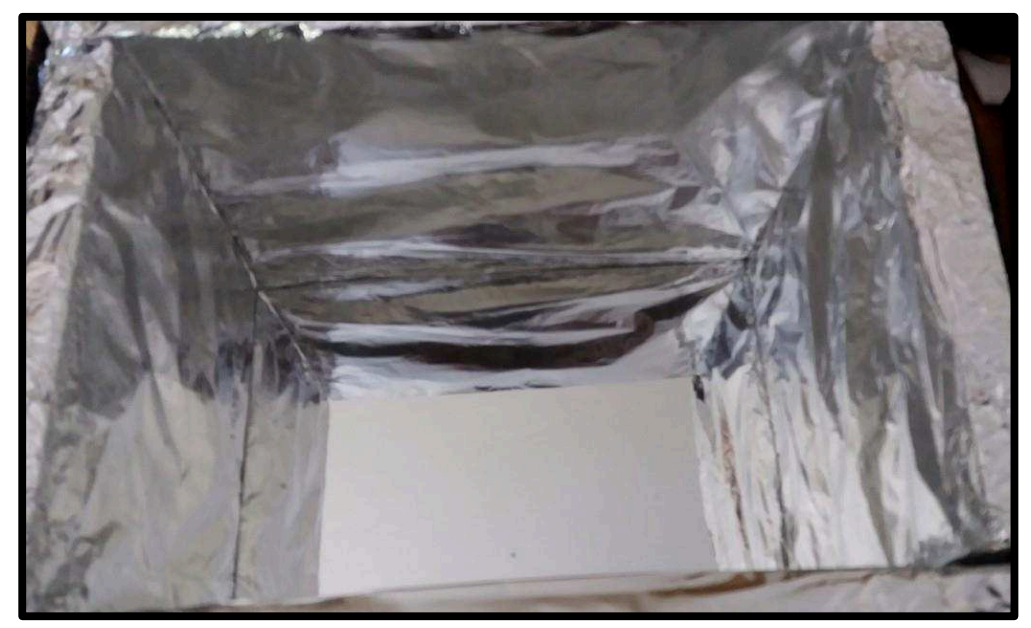

Fig. 3 - Acabamento em papel alumínio feito no forno solar construído pelo grupo G5. Fonte: Grupo G5.

Quadro 4 - Justificativas para a utilização de espelhos e/ou papel alumínio.

\begin{tabular}{|c|c|}
\hline Grupo & Material/Propriedade: refletividade \\
\hline G1 & $\begin{array}{l}\text { "O papel alumínio possui uma função importante semelhante aos espelhos, pois } \\
\text { sua parte brilhante reflete todo calor que chega até ele [...] os raios batem nos } \\
\text { refletores com espelhos e são direcionados para o interior da caixa". }\end{array}$ \\
\hline G2 & $\begin{array}{l}\text { "A utilização do papel alumínio no interior da caixa se deve a alta taxa de refleti- } \\
\text { vidade do material que possibilita a maior reflexão do calor para o centro e man- } \\
\text { ter o calor dentro da caixa menor". }\end{array}$ \\
\hline G3 & $\begin{array}{l}\text { "Colocamos também essas chapas de papelão forradas de alumínio com a inten- } \\
\text { ção de que o sol batesse nela e entrasse pela abertura". }\end{array}$ \\
\hline G4 & $\begin{array}{l}\text { "Usamos o alumínio e espelho porque ambos são bons refletores, auxiliando no } \\
\text { direcionamento da radiação ao interior da caixa". }\end{array}$ \\
\hline G5 & $\begin{array}{l}\text { "Encapamos os isopores com papel alumínio e os colocamos dentro da caixa jun- } \\
\text { tamente com um espelho, que são bons refletores de energia". }\end{array}$ \\
\hline G6 & 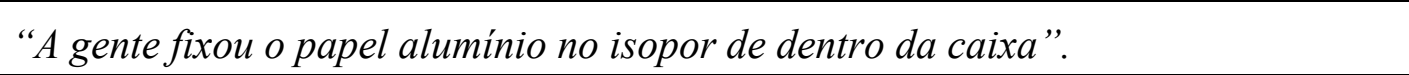 \\
\hline
\end{tabular}


Referindo-se à Situação 5, os grupos utilizaram vidro e/ou plástico para fazer o fechamento superior do forno. O Quadro 5 mostra as justificativas dos alunos para essa escolha. A utilização exacerbada de vidros em edificações em algumas zonas bioclimáticas, fazendo o contraponto com o forno solar, ocasiona um grande desconforto térmico, haja vista que

\begin{abstract}
a maior parte da radiação solar incidente, que é transmitida pelos vidros, é absorvida pelas superfícies internas e pelos objetos, aquecendo-os. Essas superfícies aquecidas no interior do ambiente emitem radiação de onda longa, a qual não passa pelo vidro, o que causa um efeito térmico conhecido como efeito estufa, pois o calor fica "preso" dentro do ambiente (DUART et al., 2016, p. 179).
\end{abstract}

Esse entendimento fica claro nas respostas dos grupos G1, G2, G3 e G5, por mais que não seja explicitado com maior riqueza de detalhes. Já os grupos G4 e G6, embora tenham usado esses materiais na constituição do forno, não explicam o motivo da escolha. Além disso, os grupos G4 e G5 utilizaram filme plástico, enquanto o G6 usou uma pasta plástica, que, em contraposição com o vidro, atenuam esse chamado efeito estufa, o que pode fazer com que a eficiência do forno fique comprometida.

Quadro 5 - Justificativas para a utilização de vidros ou plástico para fechamento do forno.

\begin{tabular}{|c|l|}
\hline Grupo & \multicolumn{1}{|c|}{ Material/Propriedade: efeito estufa } \\
\hline G1 & $\begin{array}{l}\text { "A chapa de vidro transparente permite a entrada de luz e calor, e ao mesmo } \\
\text { tempo, impede que saiam, causando o chamado "efeito estufa". }\end{array}$ \\
\hline G2 & $\begin{array}{l}\text { "Para impedir que o calor se disperse pela parte superior da caixa, será colocado } \\
\text { vidro como tampa e que permite a entrada da radiação solar, aquecendo o } \\
\text { interior da caixa". }\end{array}$ \\
\hline G3 & $\begin{array}{l}\text { "Pelo menos uma superfície da caixa deve ser transparente e estar voltada para o } \\
\text { sol para permitir o aquecimento pelo efeito estufa". }\end{array}$ \\
\hline G5 & $\begin{array}{l}\text { "A gente usou plástico para aquecer o forno". } \\
\text { "Cormite a entrada de luz solar dentro do forno". }\end{array}$ \\
\hline G6 & \begin{tabular}{l} 
"Colocamos uma pasta plástica transparente de tampa do forno". \\
\hline
\end{tabular}
\end{tabular}

A questão do efeito estufa aplicado ao forno teve expressiva discussão nas aulas e nos momentos de assessoramento uma vez que os alunos se preocuparam em ter um bom isolamento térmico no forno, que o protótipo absorvesse uma parcela significativa da radiação solar, bem como refletisse a maior parte dessa radiação para seu interior. Mas, para além dessas propriedades, o fechamento superior do forno tem um peso grande na sua eficiência.

Nesse sentido, no momento da discussão da Situação 5, os alunos trouxeram para o debate o fato de o material usado como tampa precisar ser transparente à radiação solar, mas 
opaco ao infravermelho (onda longa), uma vez que a luz solar "em contato com os objetos, aumenta a vibração das partículas dos mesmos, que acabam, então produzindo infravermelhos, que não conseguem sair do local, deixando-o aquecido" (aluno P). Resposta semelhante trazida nas discussões e que ilustra o fenômeno do efeito estufa é que "as ondas eletromagnéticas entram em forma de ondas curtas e, dependendo do tipo de vidro, as ondas que deveriam sair (longas) permanecem ali dentro" (aluno $\mathbf{H}$ ).

Como já dissertado, nos episódios de ensino-aprendizagem, sempre procurávamos fazer o contraponto do forno solar com as edificações e, especificamente no caso do efeito estufa, a utilização do vidro pode ser entendida a partir do fator solar, que corresponde à "razão entre a quantidade de energia solar que atravessa a janela pelo que nela incide" (LAMBERTS; DUTRA; PEREIRA, 2014). De acordo com os autores, o fator solar de um vidro transparente simples é de 0,87 , enquanto o do vidro transparente cinza é de 0,72 . Novamente esses dados justificam a escolha dos alunos por materiais transparente (especialmente o vidro simples), opacos à radiação de onda longa.

A Fig. 4 mostra o forno solar finalizado, construído pelo grupo G4, no qual dá pra perceber o fechamento superior com vidro transparente.

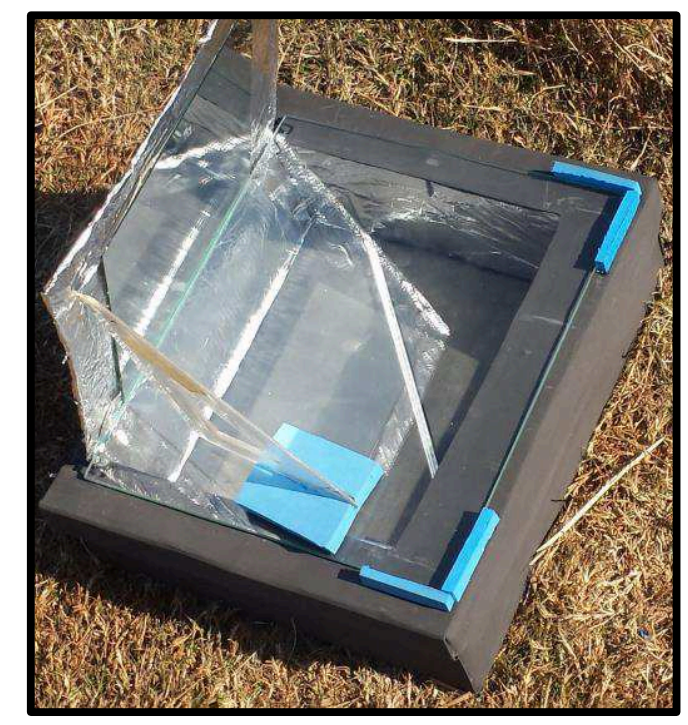

Fig. 4 - Forno solar construído pelo grupo G4, com fechamento superior em vidro. Fonte: Grupo $\mathbf{G 4}$.

Com o emprego dos materiais listados acima e justificados a partir de conceitos referentes às situações norteadoras, os fornos atingiram as temperaturas apresentadas no Quadro 6. Fazendo o contraponto do forno solar, o grupo G1 argumentou que para melhorar o conforto térmico de uma edificação pode-se "colocar parede dupla e colocar uma camada de isopor no meio das duas paredes, assim como foi deixado a camada de ar aqui (no forno); botar um tijolo seis furos, camada de ar ainda, com duas paredes, a parede vai ficar grossa [...] aque- 
les prédios de vidro, os arranha-céus, que são completamente de vidro dos lados, aí acaba virando um forno também".

Quadro 6 - Máximas temperaturas atingidas pelos fornos solares.

\begin{tabular}{|c|c|}
\hline Grupo & Máxima temperatura atingida \\
\hline G1 & $128^{\circ} \mathrm{C}$ \\
\hline G2 & $91^{\circ} \mathrm{C}$ \\
\hline G3 & $46^{\circ} \mathrm{C}$ \\
\hline G4 & $77^{\circ} \mathrm{C}$ \\
\hline G5 & $54^{\circ} \mathrm{C}$ \\
\hline G6 & $61^{\circ} \mathrm{C}$ \\
\hline
\end{tabular}

A diferença entre os valores alcançados pelos fornos está associada à escolha dos materiais e à vedação realizada. Também, embora o grupo G1 tenha alcançado uma boa eficiência, cabe destacar que os testes foram realizados no período do outono no qual a radiação solar não é tão intensa. A partir dos dados deste mesmo grupo, foi possível fazer uma discussão sobre as dificuldades existentes em se trabalhar com materiais simples, uma vez que o forno foi danificado, perdendo vedação (derretimento de material), em função da alta temperatura, como pode ser visto na Fig. 5.

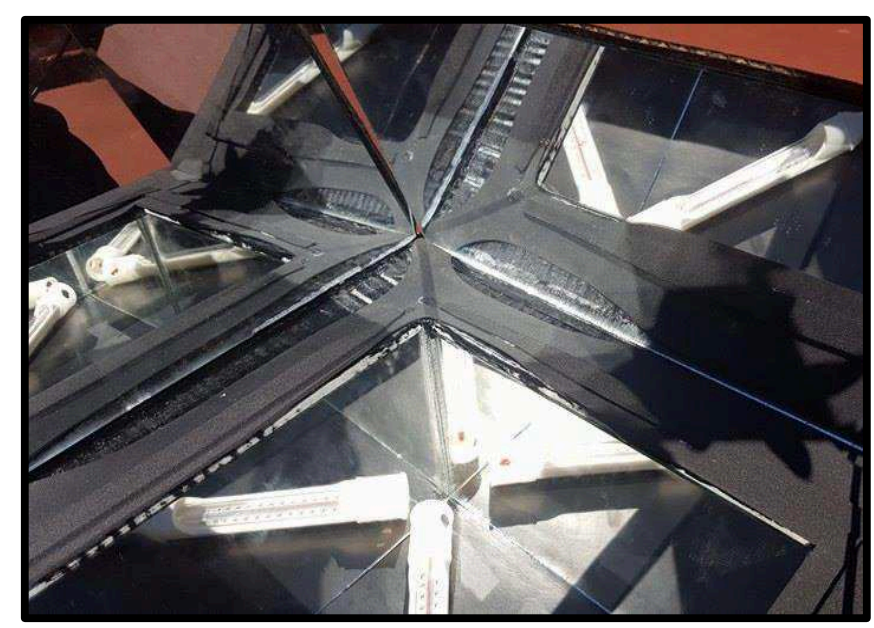

Fig. 5 - Derretimento de EVA e borracha do forno do grupo $\mathbf{G 1}$ em função da alta temperatura. Fonte: Grupo $\mathbf{G 1}$.

Fazendo a sistematização do trabalho, apesar de termos indicativos de aprendizagem significativa e/ou significativa crítica a partir das discussões em sala de aula e da própria apresentação do forno, ouvimos falas de alunos que corroboram essa percepção e que justificam a 
interdisciplinaridade, tais como "para a construção do forno, utilizamos coisas que aprendemos nas duas disciplinas. Os melhores materiais, como usá-los, as cores [...] E isso contribuiu para facilitar essa ligação entre as duas disciplinas" (aluno D) e "tivemos que escolher materiais adequados para a situação proposta. Tivemos que analisar como cada material se comporta frente ao fluxo de calor" (aluno P). A partir dessas falas, cabe fazermos alguns apontamentos sobre a evolução do conceito de calor e sobre o trabalho interdisciplinar.

No início da investigação, ao serem questionados sobre o que é calor, os alunos expressaram esse conceito físico como sensação térmica associada a temperaturas elevadas ou como uma característica intrínseca dos corpos, que pode ser ganhada ou perdida. Nenhum aluno indicou calor como sendo uma energia em trânsito quando existe diferença de temperatura entre corpos. Após a finalização do trabalho, a maioria dos alunos não substituiu o entendimento para conceito, o que confirma resultados de trabalhos descritos na literatura. Sobre as concepções deste conceito,

\begin{abstract}
a teoria do calórico e a idéia do calor como oposição ao frio, como entidade física, idéias há muito descontruídas pela física, ainda persistem no senso comum porque são suficientes para a vida diária. Continuamos a falar que nossos casacos nos "protegem" do frio, que devemos fechar a geladeira porque senão o "frio" sai. Trata-se de um conhecimento essencialmente pragmático, cujo caráter de validade na esfera cotidiana da vida é sua funcionalidade (LOPES, 1999, 143)
\end{abstract}

Embora desejássemos que cada aluno utilizasse os conceitos na sua forma correta, sabemos que ele "não esquece ou simplesmente substitui seus conceitos intuitivos e, por diversas vezes, mesmo tendo sido trabalhados os conceitos científicos, recorre a eles para resolver suas situações-problema nas aulas de Física e no seu cotidiano fora da sala de aula" (FACCHINELLO; MOREIRA, 2008, p. 9). Contudo, em determinados fragmentos, tal como em "o ar é um bom isolante térmico [...] interrompendo parte do tendencial fluxo de calor para o meio externo, que é mais frio" (aluno P), foi possível perceber que alguns alunos significam calor de forma mais correta cientificamente, expressando a relação de que há fluxo de energia na forma de calor quando existe uma diferença de temperatura.

Ao fomentarmos a pesquisa e desenvolvermos o trabalho a partir dos conhecimentos construídos pelos alunos, almejamos que evoluíssem cognitivamente no campo conceitual da calorimetria, enfatizando que

\footnotetext{
nunca abandonamos nossas concepções espontâneas, mas convivemos com idéias, algumas inclusive antagônicas, aplicáveis em contextos distintos. (...) O questionamento ao senso comum, às idéias prévias dos estudantes, implica definir em quais contextos elas são plausiveis e frutíferas, e em quais outros elas se apresentam como erros (LOPES, 1999, p. 205).
}

Sabemos também que a formação de um conceito demora um período de tempo longo, com avanços e retrocessos, interações e desníveis, o que pode ser outro indicativo da pre- 
valência de uma forma de se expressar que não é cientificamente aceita. Por mais que o conceito de calor seja central no campo conceitual pesquisado, outros conceitos também se tornaram significativos para os alunos, conforme pôde ser visto nos quadros acima.

O trabalho interdisciplinar teve uma influência expressiva nesse resultado, como relatado por alguns alunos: "os materiais que revestem nossas casas possuem suas devidas funções, assim como os que compuseram o forno, e devem assegurar nosso conforto. É importante analisar e ressaltar os aspectos que estudamos em comum nas aulas de física e conforto a respeito dos conceitos de calorimetria" (aluno E); "foi possível favorecer a integração, principalmente através de aulas práticas, na elaboração do forno solar" (aluno P) e "o trabalho contribuiu muito para a minha aprendizagem visto que relacionou os conceitos aprendidos em aula em uma atividade prática, contribuindo também para a minha formação como técnico em edificações" (aluno P).

Além do entendimento dos conceitos relacionados às disciplinas, alguns alunos também trouxeram destaques que indicam uma aprendizagem significativa crítica referente à sociedade, ao afirmarem, por exemplo, que os "fornos solares são equipamentos sustentáveis, de custos acessiveis, que trazem economia e conservam o meio ambiente, utilizando apenas a energia limpa do sol" (grupo G3) e também indicando aspectos relativos à utilização histórica desses dispositivos, destacando que "a partir de 1950 os fornos solares começaram a ser estudados com o apoio das Nações Unidas; muitos programas foram criados para difusão dessa tecnologia, principalmente em países pobres da Ásia e África, refugiados de guerras civis e regiões desertificadas" (grupo G3), que novamente permitem uma reflexão crítica.

\section{Considerações finais}

Como se pôde perceber, as situações norteadoras abarcaram diversos conceitos importantes da calorimetria e que convergem com as propriedades dos materiais utilizados nas edificações, para proporcionar conforto térmico. Como os alunos é que deveriam buscar as respostas para posterior debate com os colegas, isso favoreceu que os conceitos fossem sistematizados a partir das concepções e entendimentos deles, promovendo a diversidade de estratégias apontadas por Moreira (2006, 2009 e 2010) como forma de propiciar a aprendizagem significativa crítica.

A tarefa de construção do forno cumpriu com as expectativas, pois além de permitir que os alunos relacionassem os conceitos da física e do conforto das edificações, proporcionou o entendimento desses conceitos em situações práticas. Isso justifica nossa defesa do referencial da interdisciplinaridade e da aprendizagem significativa e/ou significativa crítica, já que o fazer interdisciplinar agrega as concepções prévias dos alunos para a compreensão de um fenômeno que, uma disciplina sozinha, provavelmente não daria conta de elucidar.

O forno solar permitiu que os alunos, além de darem sentido aos conceitos trabalhados, aplicassem os mesmos para resolver o problema que tinham recebido e, para o 
qual, deveriam buscar responder às situações propostas. Além disso, foi possível identificar na fala dos alunos que estes percebem carência de trabalhos interdisciplinares, mas reconhecem sua importância ao argumentar que esta abordagem "facilita a compreensão de conceitos que são parte integrante de diferentes disciplinas" (aluno D). Isso nos leva à reflexão da nossa prática docente, a qual passa, com demasiada frequência, à preocupação em desenvolver o plano de ensino de forma linear e fragmentada, sem fazer muito sentido aos alunos.

Fazendo uma avaliação do trabalho desenvolvido, os resultados obtidos são estimulantes e nos motivam a continuar porque, em vários momentos, foram identificadas evidências de aprendizagem significativa e/ou significativa crítica. Além disso, a troca interdisciplinar ocorrida entre as disciplinas corrobora com a proposta de ensino da instituição na qual foi realizada. Essa troca foi satisfatória porque os alunos faziam a relação dos conceitos abordados nas duas disciplinas, o que demonstra que conseguiam estabelecer vínculos entre os conceitos trabalhados, corroborando com aspectos da interdisciplinaridade.

Contudo, ainda pode-se aperfeiçoar o trabalho em alguns aspectos: desenvolver algumas aulas estando os dois professores juntos na sala; promover mais momentos de planejamento coletivo; desenvolver mais trabalhos avaliativos em conjunto e; propor um trabalho interdisciplinar envolvendo mais disciplinas, dentre as quais se pode citar sistemas prediais, cuja parte da ementa abarca os tópicos de instalações elétricas residenciais.

\section{Referências}

AUSUBEL, D. P. Aquisição e retenção de conhecimentos: uma perspectiva cognitiva. Tradução: Lígia Teopisto. 1. ed. Portugal: Editora Plátano, 2003.

BOGDAN, R. C.; BIKLEN, S. K. Investigação qualitativa em educação: uma introdução à teoria e aos métodos. Tradução: Maria João Sara dos Santos e Telmo Mourinho Baptista. Porto: Porto Editora, 1994.

BORGES, A. T. Novos rumos para o laboratório escolar de ciências. Caderno Brasileiro de Ensino de Física, Florianópolis, v. 19, n. 3, p. 291-313, dez. 2002. Disponível em: $<$ https://periodicos.ufsc.br/index.php/fisica/article/view/6607/6099>. Acesso em: 11 jun. 2018.

BRASIL. Lei n. 11.892. Institui a Rede Federal de Educação Profissional, Científica e Tecnológica, cria os Institutos Federais de Educação, Ciência e Tecnologia, e dá outras providências. Diário Oficial da União, 29 de dezembro de 2008. Disponível em: <http://www.planalto.gov.br/ccivil_03/_ato2007-2010/2008/lei/111892.htm>. Acesso em: 11 jun. 2018.

BRASIL. Instituto Federal de Educação, Ciência e Tecnologia Farroupilha. Projeto Pedagógico do Curso Técnico em Edificações Integrado. Instituto Federal Farroupilha, Santa Rosa, 
2014. Disponível em: <www.sr.iffarroupilha.edu.br/site/midias/arquivos/201509122043986 tecnico_em_edificacoes_integrado.pdf>. Acesso em: 11 jun. 2018.

CASTELLAR, S. M.; MORAES, J. V. Um currículo integrado e uma prática escolar interdisciplinar: possibilidades para uma aprendizagem significativa. In: CASTELLAR, S. M.; MUNHOZ, G. B. (Org.). Conhecimentos escolares e caminhos metodológicos. São Paulo: Xamã, 2012.

COSTA, C. Interdisciplinaridade: das concepções às representações de práticas de professores de ciências. In: CASTELlAR, S. M.; MUNHOZ, G. B. (Org.). Conhecimentos escolares e caminhos metodológicos. São Paulo: Xamã, 2012.

DUART, M. A. et. al. Materiais de Construção. Curitiba: Livro Técnico, 2016.

FACCHINELLO, C. S. Uma alternativa para o ensino da dinâmica a partir da resolução qualitativa de problemas. 2008. 177 f. Dissertação (Mestrado Profissional em Ensino de Física) - Programa de Pós-Graduação em Ensino de Física, UFRGS, Porto Alegre. Disponível em: <http://www.lume.ufrgs.br/handle/10183/17571>. Acesso em: 11 jun. 2018.

HEWITT, P. G. Física Conceitual. Tradução: Trieste Freire Ricci. 9. ed. Porto Alegre: Bookman, 2002.

JAPIASSU, H. Interdisciplinaridade e patologia do saber. Rio de Janeiro: Imago, 1976.

LAMBERTS, R.; DUTRA, L.; PEREIRA, F. O. R. Eficiência energética na arquitetura. 3. ed. Rio de Janeiro: Eletrobrás/Procel, 2014.

LOPES, A. R. C. Conhecimento escolar: ciência e cotidiano. Rio de Janeiro: Uderj, 1999.

MOREIRA, M. A. A teoria da aprendizagem significativa. Subsídios Teóricos para o Professor Pesquisador em Ensino de Ciências, Porto Alegre, 2009, 2016. Disponível em: < http://moreira.if.ufrgs.br/Subsidios6.pdf>. Acesso em: 11 jun. 2018.

MOREIRA, M. A. Abandono da narrativa, ensino centrado no aluno e aprender a aprender criticamente. In: ENCONTRO NACIONAL DE ENSINO DE CIÊNCIAS DA SAÚDE E DO AMBIENTE, 2, 2010, Niterói/RJ, ENCONTRO INTERNACIONAL DE APRENDIZAGEM SIGNIFICATIVA, 6, 2010, São Paulo/SP e ENCONTRO NACIONAL DE APRENDIZAGEM SIGNIFICATIVA, 3, 2010, São Paulo. Disponível em: $<$ http://www.if.ufrgs.br/ moreira/Abandonoport.pdf>.

MOREIRA, M. A. Aprendizagem significativa subversiva. Periódico do Mestrado em Educação da Universidade Católica Dom Bosco, Campo Grande/MS, n. 21, p. 15-32, 2006.

MOREIRA, M. A. Teorias de Aprendizagem. São Paulo: EPU, 1999. 
MORIN, E. Ciência com Consciência. Tradução: Maria D. Alexandre e Maria Alice Sampaio Dória. 8. ed. Rio de Janeiro: Bertrand Brasil, 2005.

PACHECO, E. Institutos Federais: uma revolução na educação profissional e tecnológica. In: (Org.). Institutos Federais: uma revolução na educação profissional e tecnológica. Moderna: Brasília, 2011.

SANTOMÉ, J. T. Globalização e Interdisciplinaridade: o currículo integrado. Tradução: Cláudia Schilling. Porto Alegre: Artmed, 1998.

TRINDADE, D. F. Interdisciplinaridade: um novo olhar sobre as ciências. In: FAZENDA, I. C. A (Org.). O que é interdisciplinaridade? São Paulo: Cortez, 2008.

VERGNAUD, G. ¿En qué sentido la teoría de los campos conceptuales puede ayudarnos para facilitar aprendizaje significativo? Investigações em Ensino de Ciências, Porto Alegre, v.12, n. 2, p.285-302, 2007. Disponível em: <https://www.if.ufrgs.br/cref/ojs/index.php/ienci/article /view/475/277>. Acesso em: 11 jun. 2018.

VERGNAUD, G. A Comprehensive Theory of Representation for Mathematics Education. Journal of Mathematical Behavior, Denver, v. 17, n. 2, p. 167-181, 1998. Disponível em: <https://www.sciencedirect.com/science/article/pii/S0364021399800573>. Acesso em: 11 jun. 2018.

VERGNAUD, G. Psicologia do desenvolvimento cognitivo e didáctica das matemáticas. Um exemplo: as estruturas aditivas. Análise Psicológica, Lisboa, v.1, n. 5, p. 75-90, 1986. Disponível em: < http://repositorio.ispa.pt/handle/10400.12/2150>. Acesso em: 11 jun. 2018.

(cc) BY-NC-ND Direito autoral e licença de uso: Este artigo está licenciado sob uma Licença Creative Commons. 